\title{
XXXVII. Determination of the frequency of alternating currents
}

\section{Carl Kinsley M.E. A.M.}

To cite this article: Carl Kinsley M.E. A.M. (1898) XXXVII. Determination of the frequency of alternating currents, Philosophical Magazine Series 5, 45:275, 339-347, DOI:

10.1080/14786449808621141

To link to this article: http://dx.doi.org/10.1080/14786449808621141

曲 Published online: 08 May 2009.

Submit your article to this journal $[\pi$

Џ Article views: 2

Q View related articles $\asymp$ 
sur la raie verte du thallium, \&c., lorsqu' une minime quantité de ces métaux ou d'un de leurs sels est placée sur le support de charbon.

"Enfin, les armatures coniques de l'électro-aimant étant remplacées par les armatures méplates, de manière que touto la longueur de la flamme sodique soit comprise entre ces armatures, les raies $D_{1}$ et $D_{2}$, préalablement renversées et élargies, présentent un double renversement (c'est-à-dire l'apparition d'une raie brillante au milieu de la raie noire élargie), lorsque l'électro-aimant est en activité."

XXXVII. Determination of the Frequency of Alternating Currents. By CaRL Kinsley, M.E., A.M.*

T using alternating currents experimentally it is necessary 1 to know their periodicity. The most simple and direct methods of measuring self-indnction, mutual induction, and capacity require this determination. While working on another subject I found that this could be done with great accuracy by means of a vibrating air-column. If a telephone receiver is used on an alternating current circuit, it will give a musical note whose fundamental-first harmonicwill have the same number of vibrations that the alternating current has periods. When the telephone is placed in front of a tube of the right length this note will be reinforced. If we can compute the velocity of sound in the air in the tube and can determine the wave-length of the sound, the number of vibrations or periods per second follows immediately;

$$
n=\frac{\mathrm{V}}{\lambda}
$$

where

$$
\begin{aligned}
n & =\text { number of periods, } \\
\lambda & =\text { the wave-length of the note, } \\
\mathrm{V}_{t} & =\text { the velocity of the sound. }
\end{aligned}
$$

Thus experimentally it is necessary to determine merely the length of the tube for the condition of maximum resonance.

The receiver should be a powerful one and placed at least $\cdot 41$ diam. from the tube. The tube should be of uniform diameter and the piston fit easily; then all the adjustments can be mado by hand.

\footnotetext{
* Communicated by the Author.
} 
Tubes $3 \mathrm{~cm}$. and larger do not need any tubes leading to the ear. Use tubes with smooth inside surface, such as glass or drawn brass.

In most alternating current work it has been found by numerous observers * that the E.M.F. and current may be considered a simple function of the number of alternations :

$$
i=\mathrm{I}_{1} \sin \omega t
$$

where $i=$ instantaneous value of current,

$I_{1}=$ maximum value of current, $\omega=2 \pi n$,

$t=$ time since the current was zero.

This is substantially true under normal working conditions, and may be assumed for alternating current computations.

The actual curve, however, may be strictly considered as the resultant of many pure sine-curves whose periods are multiples of the first harmonic: $i=\mathrm{I}_{1} \sin \omega t+\mathrm{I}_{2} \sin 2 \omega(t+a)+\mathrm{I}_{3} \sin 3 \omega(t+b)+\& \mathrm{c}$. where $i, \omega$, and $t$ are as already used,

$\mathrm{I}_{1}$ is the maximum value of the first harmonic,

$\mathrm{I}_{2} " \quad " \quad, \quad "$ " second "

$a$ and $b$ are the differences between the values of $t$ for the fundamental and the corresponding values for the overtones.

As is stated above, all terms but the first term are usually neglected.

The telephone diaphragm will therefore give a composite note containing not only the fundamental but all the higher harmonics that may bo present $\uparrow$.

A quantitive determination of the harmonics present bas not yet been made, and for the present

* Reasons for considering the above equation correct: S. P. Thompson, 'Dynamo Electric Macbinery,' 5th edition, p. 553; Rodes, Elect. Rev. vol. xxxix. p. 845 ; Bedell, ' The Principles of the Transformer,' p. 59. Curves determined from machines - among others: Bedell, Miller, and Wagner, Am. Hist. Elect. Ėng. vol. x. p. 500 ; Fleming, J. A., Elect. Rev. vol. xxxix. pp. 91, 122, \&c.

+ Dr. Steinmetz, in 'Theory and Calculation of Alternating Current Phenomena, finds that only the odd harmonics need be considered. Houston and Kennelly, Elect. World, vol. xxiii. p. 35, are of the same opinion.
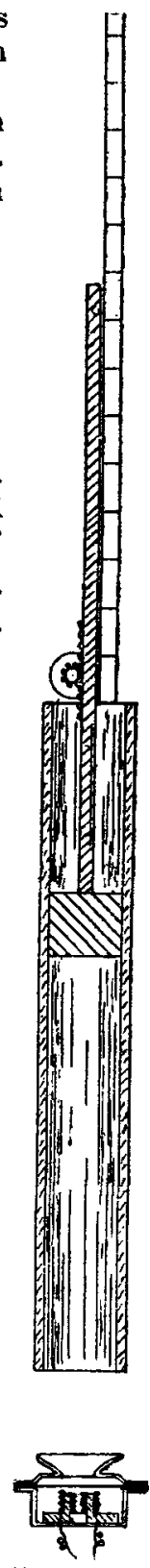

Resonance

Tube. 
purpose it is sufficient to state that in the many cases examined all of the harmonies are found. This holds up to a periodicity of 1200 per sec., which is in some cases the 36 th harmonic. It is therefore plain that any or all of the overtones may be used in the determination of the period of the fundamental. The relation between the self-induction and capacity of the circuit sometimes gives particular prominence to one of the overtones, which may be either an odd or an even harmonic.

This note may then be used most advantageously during the progress of the experiments with the alternating currents. The period of the note can be easily gotten from the accompanying tables.

\section{Use of the Tables.}

Open tubes act as though they were $0.41 d^{*}$ longer than their real length.

Then the first length of the tube giving maximum resonance will be

$$
\begin{array}{ll}
\text { will be } & l=\rho-0.41 d=\frac{1}{4} \lambda-0.41 d, \\
\text { where } & l=\text { actual length of tube, } \\
& \rho=\text { equivalent length, } \\
d & =\text { diameter of the tube, } \\
\lambda & =\text { wave-length of the sound. }
\end{array}
$$

Table II. is computed for the diameter of tube of $4 \mathrm{~cm}$. and so the correction to be added to $l$ will not be constant.

Add the correction gotten from Table I. to the observed value of $l$, and in the column for the temperature of the tube find the frequency corresponding to the length. Divide this periodicity by the number of the harmonic, and the periodicity of the fundamental will be the result.

The frequency of the fundamental will be the greatest common divisor of the frequencies of successive harmonics. Having gotten by trial the number of the harmonic most advantageous to use, that harmonic alone may hereafter be used.

As an illustration a typical case will be given :

Let $t=$ temperature of the tube, $c=$ correction gotten from Table I. $n, n_{2}, n_{3}$, \&c. periodicity of fundamental, second harmonic, third, \&c.

$$
d=5 \mathrm{~cm} . \quad t=20^{\circ} \mathrm{C} .
$$

(1) $l=21 \cdot 68, \quad c=2 \cdot 02, \quad \rho=23 \cdot 70, \quad n_{\mathrm{p}}=360 \cdot 00$,

(2) $l=18.30, \quad c=2.02, \quad \rho=20.32, \quad n_{\mathrm{B}}=420.2$.

By inspection No. (1) is found to be the sixth harmonic, and No. (2) the seventh. The fundamental which is the highest common divisor is then $60^{\circ} 0$.

* Lord Rayleigh, 'Theory of Sound,' vol, ii. p. 295. 
A slight difference might be caused by the change in period which is continually occurring under usual conditions. If now No. 1 should be read again it might give

(3) $\quad l=21 \cdot 72, \quad c=2 \cdot 02, \quad \rho=23 \cdot 74, \quad n_{6}=359 \cdot 4$.

Then the fundamental would be $n=59 \cdot 9$.

\section{TABle I.}

Correction to be added to observed length.

\begin{tabular}{|c|c|c|c|c|c|c|c|}
\hline \multirow{2}{*}{$\begin{array}{l}\text { Observed } \\
\text { length. }\end{array}$} & \multicolumn{7}{|c|}{ Diameter of tubes in $\mathrm{cm}$. } \\
\hline & 1. & 2. & 3. & 4. & 5. & 6. & 7. \\
\hline 6 & $\cdot 46$ & $\cdot 84$ & $1 \cdot 24$ & $1 \cdot 64$ & $2 \cdot 04$ & $2 \cdot 45$ & 286 \\
\hline 7 & 48 & $\cdot 85$ & $" 1$ & $n$ & $"$ & $"$ & $2 \cdot 85$ \\
\hline 8 & $\cdot 50$ & .85 & $"$ & $"$ & $"$ & $"$ & $"$ \\
\hline 9 & .52 & 86 & $"$ & $"$ & $"$ & $2 \cdot 44$ & $"$ \\
\hline 10 & $\cdot 54$ & 86 & $"$ & $"$ & $"$ & $"$ & $2 \cdot 84$ \\
\hline 11 & 56 & 87 & 1.25 & " & $"$ & $"$ & $"$ \\
\hline 12 & 58 & .87 & $"$ & $"$ & " & " & $"$ \\
\hline 13 & $\cdot 60$ & .88 & " & " & $2 \cdot u 3$ & $2 \cdot 43$ & $2 \cdot 83$ \\
\hline 14 & 62 & .89 & $"$ & ” & $"$ & $"$ & $"$ \\
\hline 15 & 64 & .89 & $1 \cdot 26$ & $"$ & " & $"$ & $"$ \\
\hline 16 & $\cdot 66$ & .90 & $"$ & $"$ & $"$ & $"$ & 282 \\
\hline 17 & $\cdot 68$ & .91 & $"$ & $"$ & $"$ & $2 \cdot 42$ & $"$ \\
\hline 18 & $\cdot 71$ & .92 & " & $"$ & $2 \cdot 02$ & $"$ & $"$ \\
\hline 19 & $\cdot 73$ & .93 & 1.27 & " & $"$ & $"$ & $2 \cdot 81$ \\
\hline 20 & 75 & .94 & $"$ & $"$ & ", & $"$ & " \\
\hline 21 & $\cdot 78$ & $\cdot 94$ & " & " & $"$ & $2 \cdot 41$ & $"$ \\
\hline 22 & $\cdot 81$ & .95 & $"$ & " & , & ", & $2 \cdot 80$ \\
\hline 23 & $\cdot 84$ & $\cdot 96$ & $1 \cdot 28$ & " & 2.01 & , & " \\
\hline 24 & .87 & .97 & $"$ & $"$ & $"$ & $"$ & $"$ \\
\hline 25 & 90 & .98 & $"$ & " & $"$ & $2 \cdot 40$ & $2 \cdot 79$ \\
\hline 26 & .93 & $\cdot 99$ & 1.29 & $"$ & ", & $"$ & $"$ \\
\hline 27 & 96 & 1.00 & $"$ & " & $"$ & $"$ & $"$ \\
\hline 28 & $\cdot 99$ & 1.01 & $"$ & ," & 200 & ", & $2 \cdot 78$ \\
\hline 29 & 1.02 & 1.02 & $1 \cdot 30$ & $"$ & $"$ & $2 \cdot 39$ & $"$ \\
\hline 30 & 1.05 & 1.03 & $"$ & $"$ & $"$ & $"$ & $"$ \\
\hline 31 & 108 & 1.04 & $"$ & " & $"$ & $"$ & 277 \\
\hline 32 & $1 \cdot 11$ & 105 & $1 \cdot 31$ & , & 1.99 & $2 \cdot 38$ & $"$ \\
\hline 33 & $1 \cdot 15$ & $1 \cdot 06$ & $"$ & $"$ & $"$ & $"$ & 276 \\
\hline 34 & $1 \cdot 18$ & 1.07 & 132 & $"$ & " & $"$ & " \\
\hline 35 & 1.21 & 1.08 & $"$ & $"$ & " & $2 \cdot 37$ & $"$ \\
\hline
\end{tabular}


Computation of the Tables.

We have seen that

$$
\mathrm{V}_{t}=\lambda n,
$$

and so we must know the velocity of sonnd in air in the tube.

According to Kirchhoff's * equation

$$
\mathrm{V}_{0}=a\left(1-\frac{y}{d \sqrt{\pi n}}\right)
$$

where $V_{0}=$ the velocity of sound in the tube at $0^{\circ}$ temp. and 0 rapour-pressure.

$a=$ the velocity of sound in free air at $0^{\circ}$ temp. and 0 vapour-pressure.

$y=a$ constant depending on the inside surface of the tube.

Use $\quad a=330 \cdot 9, \quad y=\cdot 00799$.

The equation has been experimentally established and the constants gotten by Dr. Low + .

The velocities for any atmospheric condition can bo gotten from the equation

where $\alpha=\cdot 003665$,

$$
\mathrm{V}_{t}=\mathrm{V}_{0} \sqrt{\frac{1+a t}{1-\frac{3}{8} \overline{\mathrm{B}}}},
$$

$p=$ vapour-pressure,

$\mathrm{B}=$ barometric pressure.

The length of the tube, plus correction for open end, will thus be

$$
\begin{gathered}
\rho=l+c=\frac{\lambda}{4}=\frac{V_{t}}{4 n}=V_{0} \sqrt{\frac{1+\alpha t}{1-\frac{3}{8} \frac{p}{B}}} \div 4 n \\
\rho=\frac{a\left(1-\frac{y}{d \sqrt{\pi n}}\right) \sqrt{\frac{1+\alpha t}{1-\frac{3}{8} \frac{p}{B}}}}{4 n} .
\end{gathered}
$$

In this equation the constants known are

$$
\begin{aligned}
& a=330 \cdot 9 \text { metres per sec., } \\
& y=\cdot 00799, \\
& a=\cdot 003665 ;
\end{aligned}
$$

* Pogg. Ann. vol. cxxxiv. p. 177.

$\dagger$ Dr. Low, Phil. Mag. Sept. 1894. 
TABLE II.-Frequency of

\begin{tabular}{|c|c|c|c|c|c|c|c|c|c|c|}
\hline & & & & & nperatu & of the & tube, $t$. & & & \\
\hline & & $0^{\circ}$. & $5^{\circ}$ & $10^{\circ}$. & $13^{\circ}$ & $15^{\circ}$ & $17^{\circ}$ & $18^{\circ}$ & $19^{\circ}$. & $20^{\circ}$ \\
\hline & 7 & $1178 \cdot 1$ & $1189 \cdot 2$ & 12000 & 1206.5 & $1211 \cdot 0$ & 12154 & $1217 \cdot 5$ & 1219.8 & $1222 \cdot 0$ \\
\hline & 8 & 10307 & 10404 & $1050-0$ & $1055 \cdot 5$ & $1059 \cdot 4$ & $1063 \cdot 2$ & $1065 \cdot 0$ & 1067.0 & $1069 \cdot 0$ \\
\hline & 9 & 9160 & $924 \cdot 6$ & 9330 & $938 \cdot 0$ & $941 \cdot 4$ & 9447 & $946 \cdot 5$ & $948 \cdot 2$ & 9300 \\
\hline & 10 & $824 \cdot 2$ & 831.9 & $839 \cdot 5$ & 839.5 & $847 \cdot 1$ & $850 \cdot 1$ & $851 \cdot 6$ & $858 \cdot 2$ & $854 \cdot 8$ \\
\hline & 11 & $749 \cdot 2$ & $756 \cdot 2$ & $763 \cdot 1$ & 763.1 & 7700 & $772 \cdot 7$ & $774 \cdot 2$ & $775 \div 5$ & 777.0 \\
\hline & 12 & $686-6$ & $693 \cdot 0$ & $699 \cdot 4$ & $699 \cdot 4$ & $705 \cdot 7$ & $708 \cdot 2$ & 7095 & 7108 & 7122 \\
\hline & 13 & 6336 & $639 \cdot 6$ & $645 \cdot 4$ & $645 \cdot 4$ & $651 \cdot 3$ & 6537 & 6549 & $656 \cdot 1$ & $657 \cdot 3$ \\
\hline & 14 & $588 \cdot 2$ & 593.8 & $599 \cdot 2$ & $599 \cdot 2$ & $604 \cdot 6$ & $606 \cdot 8$ & 607.9 & $609 \cdot 0$ & $610 \cdot 2$ \\
\hline$\therefore$ & 15 & $549 \cdot 0$ & $554 \cdot 1$ & $559 \cdot 2$ & $559 \cdot 2$ & $564 \cdot 2$ & $566 \cdot 2$ & $567 \cdot 2$ & $568 \cdot 2$ & $569 \cdot 4$ \\
\hline$\approx$ & 16 & $514 \cdot 6$ & 519.4 & $524 \cdot 2$ & $524 \cdot 2$ & 528.9 & 53066 & $531 \cdot 6$ & б32.6 & $533 \cdot 7$ \\
\hline 苞 & 17 & $484 \cdot 2$ & $488 \cdot 7$ & $493 \cdot 2$ & 493.2 & $497 \cdot 7$ & $499 \cdot 4$ & $500 \cdot 2$ & $501 \cdot 2$ & $502 \cdot 2$ \\
\hline है & 18 & $457 \cdot 2$ & $461 \cdot 5$ & $465 \cdot 8$ & $465 \cdot 8$ & $470 \cdot 0$ & $471 \cdot 6$ & $472 \cdot 5$ & $473 \cdot 4$ & $474 \cdot 2$ \\
\hline 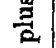 & 19 & $433 \cdot 1$ & $437 \cdot 1$ & $441 \cdot 2$ & $441 \cdot 2$ & $445 \cdot 2$ & 446.8 & $447 \cdot 6$ & $448^{\circ} 4$ & $449 \cdot 2$ \\
\hline 胥 & 20 & $411 \cdot 4$ & $415 \cdot 2$ & 4190 & $421 \cdot 3$ & $422 \cdot 8$ & $424 \cdot 4$ & $425 \cdot 1$ & 425.9 & 4267 \\
\hline 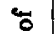 & 21 & 391.7 & 395.4 & 399.0 & 401.2 & $402 \cdot 7$ & $404 \cdot 1$ & 4048 & 4056 & $406: 3$ \\
\hline 吾 & 22 & 374.5 & $377 \cdot 4$ & $380 \cdot 8$ & $382 \cdot 8$ & $384 \cdot 3$ & 385.7 & $386 \cdot 5$ & $387 \cdot 1$ & 387.8 \\
\hline 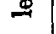 & 23 & $357 \cdot 6$ & $361 \cdot 0$ & $364 \cdot 3$ & 366.2 & $367 \cdot 6$ & 368.7 & $369 \cdot 6$ & $370 \cdot 2$ & $370 \cdot 9$ \\
\hline 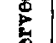 & 24 & $342 \cdot 7$ & 345.9 & $349 \cdot 1$ & 350.9 & $352 \cdot 2$ & $353 \cdot 5$ & $354 \cdot 1$ & $354 \cdot 7$ & 355.4 \\
\hline ह & 25 & 328.7 & $332 \div 1$ & 3350 & 336.9 & $338 \cdot 1$ & $339 \cdot 3$ & 340.0 & 346.0 & $341 \cdot 2$ \\
\hline & 26 & $316 \cdot 2$ & $319 \cdot 2$ & $322 \cdot 1$ & 323.8 & $325 \cdot 0$ & $326 \cdot 2$ & $326 \cdot 8$ & $327 \cdot 4$ & 328.0 \\
\hline & 27 & 304.5 & $307 \cdot 3$ & $310 \cdot 2$ & 311.9 & 3130 & $314 \cdot 1$ & 3147 & $315 \cdot 3$ & $315 \cdot 8$ \\
\hline & 28 & $293 \cdot 6$ & $296 \cdot 3$ & $299^{\circ} 0$ & $300 \cdot 7$ & $301 \cdot 8$ & $302 \cdot 8$ & $303 \cdot 4$ & 304.0 & $304 \cdot 5$ \\
\hline & 29 & $283 \cdot 4$ & $286-1$ & $288 \cdot 7$ & 2903 & $291 \cdot 3$ & $292 \cdot 4$ & 293.0 & $298 \cdot 5$ & 2940 \\
\hline & 30 & $274 \cdot 0$ & 276.6 & $279 \cdot 1$ & $280 \cdot 6$ & $281 \cdot 6$ & $282 \cdot 6$ & $283 \cdot I$ & $283 \cdot 6$ & $284 \cdot 1$ \\
\hline & 31 & $265 \cdot 1$ & $267 \cdot 6$ & 270.0 & $271 \cdot 5$ & $272: 5$ & 2735 & $274 \cdot 0$ & $274 \cdot 5$ & 275.0 \\
\hline & 32 & 256.8 & $259 \cdot 2$ & $261 \cdot 6$ & $263 \cdot 0$ & 263.9 & $264 \cdot 9$ & $265 \cdot 3$ & 265.8 & 266.3 \\
\hline & 33 & $249 \cdot 0$ & $251 \cdot 3$ & $253 \cdot 6$ & 2550 & 255.9 & 2568 & $257 \cdot 3$ & $257 \cdot 7$ & 258.2 \\
\hline & 34 & $241 \cdot 6$ & 2439 & $246 \cdot 2$ & $247 \cdot 5$ & 248.4 & $249 \cdot 2$ & 249.7 & $250 \cdot 1$ & $250 \cdot 6$ \\
\hline & 35 & $234 \cdot 7$ & $236 \cdot \theta$ & $239 \cdot 1$ & 240.4 & $241 \cdot 2$ & $242 \cdot 1$ & 242.5 & $243 \cdot 0$ & $243 \cdot 4$ \\
\hline
\end{tabular}


the Frequency of Alternating Currents.

the Alternating Current.

\begin{tabular}{|c|c|c|c|c|c|c|c|c|}
\hline \multicolumn{9}{|c|}{ Temperature of the tube, $t$. } \\
\hline $21^{\circ}$. & $22^{\circ}$ & $23^{\circ}$. & $24^{\circ}$ & $25^{\circ}$. & $26^{\circ}$. & $27^{\circ}$ & $28^{\circ}$ & $30^{\circ}$ \\
\hline $1224 \cdot 2$ & $1226 \cdot 5$ & 12287 & $1231 \cdot 0$ & $1233 \cdot 0$ & $1235 \cdot 4$ & $1237 \cdot 6$ & $1239 \cdot 8$ & $1244 \cdot 1$ \\
\hline $1071 \cdot 0$ & $1073 \cdot 0$ & $1074 \cdot 8$ & 10767 & $1078 \cdot 7$ & $1080 \cdot 7$ & $1082 \cdot 6$ & $1084 \cdot 6$ & $1088 \cdot 5$ \\
\hline $951 \cdot 6$ & $953 \cdot 4$ & $955 \cdot 1$ & 9569 & $958 \cdot 7$ & $960 \cdot 4$ & $962 \cdot 1$ & $964 \cdot 0$ & $967 \cdot 5$ \\
\hline $856 \cdot 3$ & $858 \cdot 0$ & $859 \cdot 5$ & $861 \cdot 0$ & 8626 & $864 \cdot 2$ & $865 \cdot 8$ & $867 \cdot 4$ & $870 \cdot 5$ \\
\hline $778 \cdot 4$ & $779 \cdot 8$ & $781 \cdot 2$ & $782 \cdot 5$ & $784 \cdot 0$ & $785 \cdot 5$ & $786 \cdot 9$ & $788 \cdot 2$ & $791 \cdot 0$ \\
\hline $713: 5$ & $714 \cdot 8$ & $716 \cdot 0$ & $717 \cdot 4$ & $718 \cdot 6$ & $720 \cdot 0$ & $721 \cdot 4$ & $722: 7$ & $725 \cdot 3$ \\
\hline $658 \cdot 5$ & $659 \cdot 7$ & $660 \cdot 9$ & $662 \cdot 1$ & $663 \cdot 2$ & $664 \cdot 5$ & 6657 & 666.9 & $669 \cdot 4$ \\
\hline $611 \cdot 3$ & $612 \cdot 4$ & 613.5 & $614 \cdot 6$ & 6157 & $616 \cdot 9$ & 618.0 & $619 \cdot 2$ & $621 \cdot 4$ \\
\hline $570 \cdot 3$ & $571 \cdot 4$ & $572 \cdot 4$ & 5735 & $574 \cdot 6$ & $575 \cdot 5$ & 576.5 & $577 \cdot 6$ & $579 \cdot 8$ \\
\hline $534 \cdot 5$ & $535 \cdot 5$ & 5365 & $537 \cdot 5$ & $538 \cdot 5$ & $539 \cdot 5$ & 5405 & $541 \cdot 5$ & 543.5 \\
\hline $503 \cdot 0$ & $504 \cdot 0$ & $504 \cdot 9$ & $505 \cdot 8$ & 5068 & $507 \cdot 7$ & 5086 & $509 \cdot 5$ & $511 \cdot 5$ \\
\hline $475 \cdot 0$ & 475.9 & 476.8 & $477 \cdot 6$ & $478 \cdot 6$ & $479 \cdot 5$ & $480 \cdot 3$ & $481 \cdot 2$ & $483 \cdot 0$ \\
\hline 4500 & $450 \cdot 8$ & $451 \cdot 6$ & $452 \cdot 4$ & $453 \cdot 3$ & $454 \cdot 0$ & $454: 8$ & $455^{\circ} 6$ & $457 \cdot 4$ \\
\hline 4274 & $428 \cdot 2$ & 4290 & $429 \cdot 8$ & $430 \cdot 6$ & $431 \cdot 3$ & $432 \cdot 1$ & 432.9 & $434 \cdot 4$ \\
\hline $407 \cdot 1$ & $407 \cdot 8$ & $408 \cdot 5$ & $409 \cdot 3$ & 4100 & 4107 & $411 \cdot 5$ & $412 \cdot 2$ & $413 \cdot 8$ \\
\hline $388 \cdot 5$ & $389 \cdot 2$ & $389 \cdot 9$ & $390 \cdot 6$ & $391 \cdot 3$ & $392 \cdot 0$ & $392 \cdot 7$ & $393 \cdot 4$ & 394.9 \\
\hline 3716 & 3722 & $372 \cdot 9$ & $373 \cdot 6$ & $374: 3$ & $375 \cdot 0$ & 3757 & $376 \cdot 4$ & $377 \cdot 7$ \\
\hline $356 \cdot 0$ & $356 \cdot 7$ & $357 \cdot 4$ & $358^{\circ} 0$ & $358 \cdot 7$ & $359 \cdot 4$ & $360 \cdot 0$ & 3607 & $362 \cdot 0$ \\
\hline $342 \cdot 8$ & $342 \cdot 5$ & $348 \cdot 1$ & $343 \cdot 7$ & $344 \cdot 3$ & $344 \cdot 9$ & $345 \cdot 5$ & $346 \cdot 2$ & $347 \cdot 4$ \\
\hline $328 \cdot 6$ & $329 \cdot 2$ & $329 \cdot 8$ & $330 \cdot 4$ & $331 \cdot 0$ & $331 \cdot 6$ & $332 \cdot 2$ & $332 \cdot 8$ & $334 \cdot 0$ \\
\hline $316^{* 4}$ & $317 \cdot 0$ & $317 \cdot 6$ & $318 \cdot 1$ & 318.7 & $319 \cdot 3$ & $319 \cdot 9$ & $320 \cdot 5$ & $321 \cdot 6$ \\
\hline $305 \cdot 1$ & $305 \cdot 6$ & 3062 & 306.8 & $307 \cdot 3$ & $307 \cdot 9$ & $308 \cdot 5$ & $309 \cdot 0$ & $310 \cdot 2$ \\
\hline $294 \cdot 5$ & $295 \cdot 1$ & $295 \cdot 6$ & $296 \cdot 1$ & 2967 & $297 \cdot 2$ & $297 \cdot 7$ & $298 \cdot 3$ & $299 \cdot 3$ \\
\hline 284.7 & $285 \cdot 2$ & 2857 & $286 \cdot 2$ & 2867 & $287 \cdot 2$ & $287 \cdot 8$ & $288 \cdot 3$ & $289 \cdot 3$ \\
\hline 275.5 & 2760 & 276.5 & $277 \cdot 0$ & $277 \cdot 5$ & $278 \cdot 0$ & 278.5 & 279.0 & 280.0 \\
\hline 2668 & $267 \cdot 3$ & $267 \cdot 8$ & $268 \cdot 3$ & $268 \cdot 8$ & $269 \cdot 3$ & $269 \cdot 8$ & 270.2 & $271 \cdot 2$ \\
\hline $258 \cdot 7$ & $259 \cdot 1$ & $259 \cdot 6$ & $260 \cdot 1$ & $260 \cdot 6$ & $261 \cdot 1$ & $261 \cdot 5$ & $262 \cdot 0$ & $262 \cdot 9$ \\
\hline $251 \cdot 0$ & $251 \cdot 5$ & $252 \cdot 0$ & $252 \cdot 4$ & $252 \cdot 9$ & $253 \cdot 4$ & 2538 & $254: 3$ & $255 \cdot 2$ \\
\hline $243 \cdot 8$ & $244 \cdot 3$ & $244 \cdot 8$ & $245 \cdot 2$ & $245 \cdot 7$ & $246 \cdot 1$ & $240 \cdot 6$ & 247.0 & $248 \cdot 6$ \\
\hline
\end{tabular}


and the constants assumed are

$$
\begin{aligned}
& p=\frac{1}{3} \text { saturation for the different temperatures, } \\
& \mathrm{B}=760 \mathrm{~mm} \text {. of mercury, } \\
& d=4 \mathrm{~cm} \text {. in Table II. }
\end{aligned}
$$

Since $d$ is assumed to be $4 \mathrm{~cm}$. in Table II. the quantity to be added to $l$ will be $0.41 d=1.64$ for every note when a tube of that diameter is used.

For other tubes the correction will vary for different $l$ s due to the changing $V_{0}$ for the different tubes. Table $I$. gives this correction for all tubes apt to be used.

The error in reading $l$ is very small and need be only a fraction of a millimetre in any case.

The greatest possible error due to the assumption of $\frac{1}{3}$ saturation will be, at $20^{\circ} \mathrm{C}$., only $+\frac{1}{4}$ per cent. when $p$ is 100 per cent. of saturation and $-\frac{1}{4}$ per cent. for zero vapour in the air.

Consequently for engineering measurements the error will be less than that due to other instruments, and so may be neglected. The adjustment for maximum resonance can be made with greater rapidity than that with which a Siemens dynamometer or a Thomson balance ean be used. This makes it possible to use an ordinary alternating current circuit for accurate experimental work.

The tube that will be found most durable, uniform, and convenient will be a drawn brass tube $4 \mathrm{~cm}$. in diameter.

The writer has very carefully compared glass and drawn brass tubes, and finds that $y$ is the same for each. He has also measured the velocities of sound using a chronograph to determine $n$, and finds that the value for $a$ already given can be used without sensible error.

The uniform internal diameter of the brass tube makes it much more convenient for use, as a dry piston can be employed.

The natural period of the diaphragm in every telephone on the market is too high to affect in any sensible way the harmonics due to the alternating current.

A number of other methods have been proposed $*$ that depend on the resonance of iron wire or strips set into vibration by the alternating current.

Besides the impossibility of making, with either, really accurate adjustments for maximum resonance-which is independent of the accuracy of the gearing-it is necessary to standardize the instrument, and that will be found impossible to do with accuracy except in a very well-equipped laboratory.

$$
\text { * Campbell, Phil. Mag., Aug. } 1896 .
$$




\section{Method for Determining the Velocity of Sound.}

The velocity of sound in air has been determined by many observers both in the free air and in air confined in tubes. The early experimenters*, of whom Moll, Von Beek, and Kuytenbrouwer in 1823 did exceptionally careful work, used composite sounds in free air. It was suggested by Le Ruux + , that the temperature measurements were incorrect. This view is supported by the observations of Nansen, who found that the temperatures gotten on the surface were at variance with that taken in his "crow's nest." Therefore, the temperature measurements of Parry and Foster $\ddagger$ certainly did not give the true temperature of the path of the sound. In 1868 M. V. Regnault § reported measurements taken both in free air and in tubes which cast so much doubt on the earlier measurements that the whole subject was reopened.

Since then, H. Scheebli \| and Dr. Low T, using pure notes, have found, from the positions of maxima in resonating tubes, the wave-length of sound. Dr. Low's relative results are particularly good; but his method of standardizing his tuning-forks and of determining the vapour-pressure of the air in the tubes is unfortunately not above criticism. His values for $a$ and $y$ must, however, be very nearly correct and so they were used in the preceding tables.

The writer would suggest that the use of a telephone as the sounding-body with the periodicity determined directly from the motor generator by means of a chronograph would be a most satisfactory method of producing the notes desired. The telephone may be enclosed if light gases are to be used. Drawn tubing with a dry piston would obviate all difficulty of determining vapour-pressure.

Washington University,

St. Louis, Mo., U.S.A.

* See paper by Le Conte, Phil. Mag., Jan. 1864.

+ Comptes Rendus, p. 392, 1867.

I Phil. Trans. p. 97, 1828.

\$ Comptes Rendus, p. 209, 1868.

if Pogg. Ann. p. 303, 1869.

7 Phil. Mag. Sept. 1894. 